\title{
SUCCESSFUL PRACTICES IN THE INTEGRATION OF THE ROMA POPULATION IN BULGARIA
}

DOI: http://dx.doi.org/10.18509/GBP.2020.46 UDC: 314.116(497.2:=214.58)"19/20"

331.5(497.2:=214.58)

\section{Georgy Burdarov}

Kristina Petrova-Hristova

Sofia university "St. Kliment Ohridski”, Bulgaria

\begin{abstract}
The Roma ethnic group is one of the most discriminated and poorly integrated groups in Bulgaria as well as in Europe. They are often present in criminal chronicles and are among the marginal population. They are typified as uneducated, lazy, criminal-related. They are characterized by low educational level and low labor activity, which leads to difficulties in their social integration. Despite the many negative aspects that have arisen against the Roma group, we can find good examples of the successful applying of integration measures. Some working models for integration have been adopted in Bulgaria. In addition, we are observing for the first time, the development and successful applying of the so-called an „Icelandic model“ for keeping vulnerable groups of children at school. It is applied to the Roma neighborhood of Straldzha town. Due to the worsening demographic situation in the country, it`s very important the successful integration of Roma and significantly increase of the education level and labor activities.
\end{abstract}

Key words: ethnic group, Roma, integration, education, labor activity, integration models

\section{ETHNIC STRUCTURE OF BULGARIAN`S POPULATION}

Ethnic structure is a category that provides information on the composition of the population by origin. The Balkans is a territory with a highly mosaic ethnic composition and a correspondingly diverse confessional composition, which in the past has been a major prerequisite for conflicts. In the book "The Clash of Civilizations", Samuel Huntington included the territory precisely as part of the so-called "axis of conflict". [1]

The ethnic composition in Bulgaria is represented by three main groups - Bulgarian, Turkish and Roma. In addition, there are representatives of other groups at a smaller percentage - Russian, Armenian, Wallachian, Macedonian, Greek, Ukrainian, Jewish and Romanian. According to the latest census (2011), the highest part of the population, logically, is the Bulgarian ethnic group $-84,8 \%$, the Turkish ethnic group traditionally ranks second with $8,8 \%$ and the Roma - with $4,9 \%$ (Fig. 1).

So far, 17 national censuses have been conducted in the country, with the ethnic category present with at least one or two attributes. But from 1956 until the end of the socialist period, the censuses not examined this category. From 1992 until now, the attributes that may be mentioned are ethnicity, mother language and religion, but the answers to these questions are voluntary.

The census data do not show any dramatic changes in the ethnic structure of the Bulgarian population. An exception is the high migration in 1989 of citizens of the 
Turkish minority - about 360,000 , for political reasons. Since then, we have seen a regular decline in the number of Bulgarians of Turkish descent, which is higher (about 158 thousand) in the period between the last two censuses, compared to the previous surveyed period (about 50 thousand). They have a constant flow of emigration to neighboring Turkey, mainly for economic reasons.

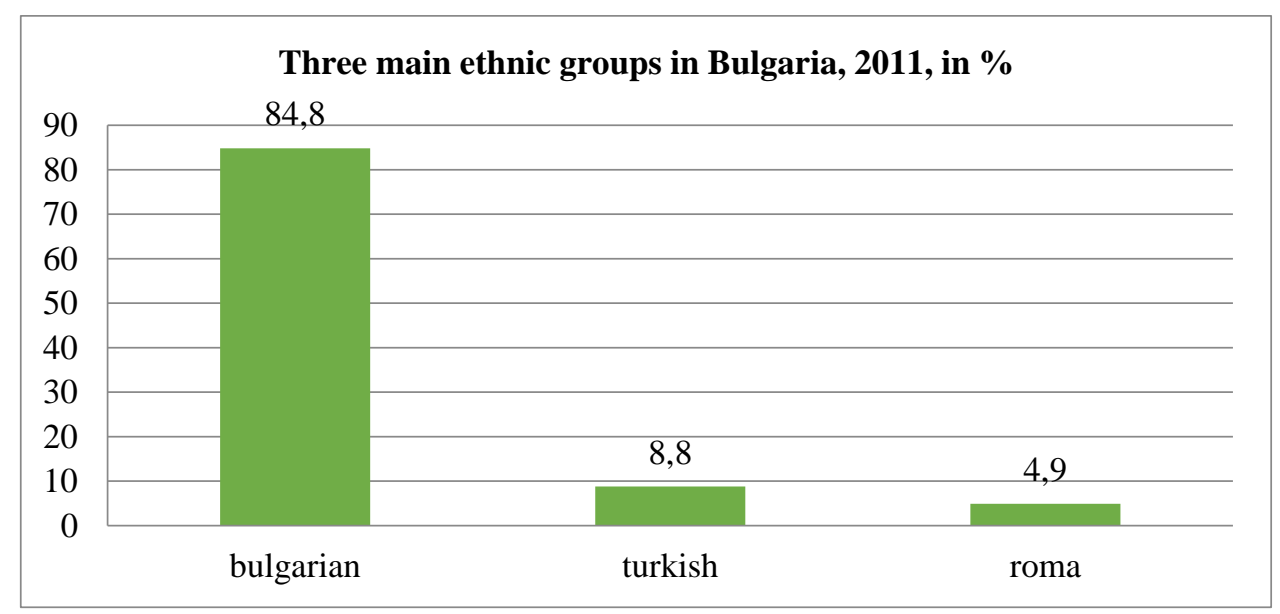

Figure1. Number of the three main ethnic groups in Bulgaria, 2011 Source: NSI

In the recent years, not only in Bulgaria but also in Europe and in the world as a whole, there has been an increasing interest in ethnic communities and in particular in their numbers, demographic development, spatial mobility and territorial location. In our country, this interest can be said to be the highest with regard to the Roma ethnic group. There are wide discrepancies between the number of Roma recorded in the official censuses and scientific and empirical research in this regard. Hence the great speculation on the subject in the public and media space. ${ }^{2}$ [2]

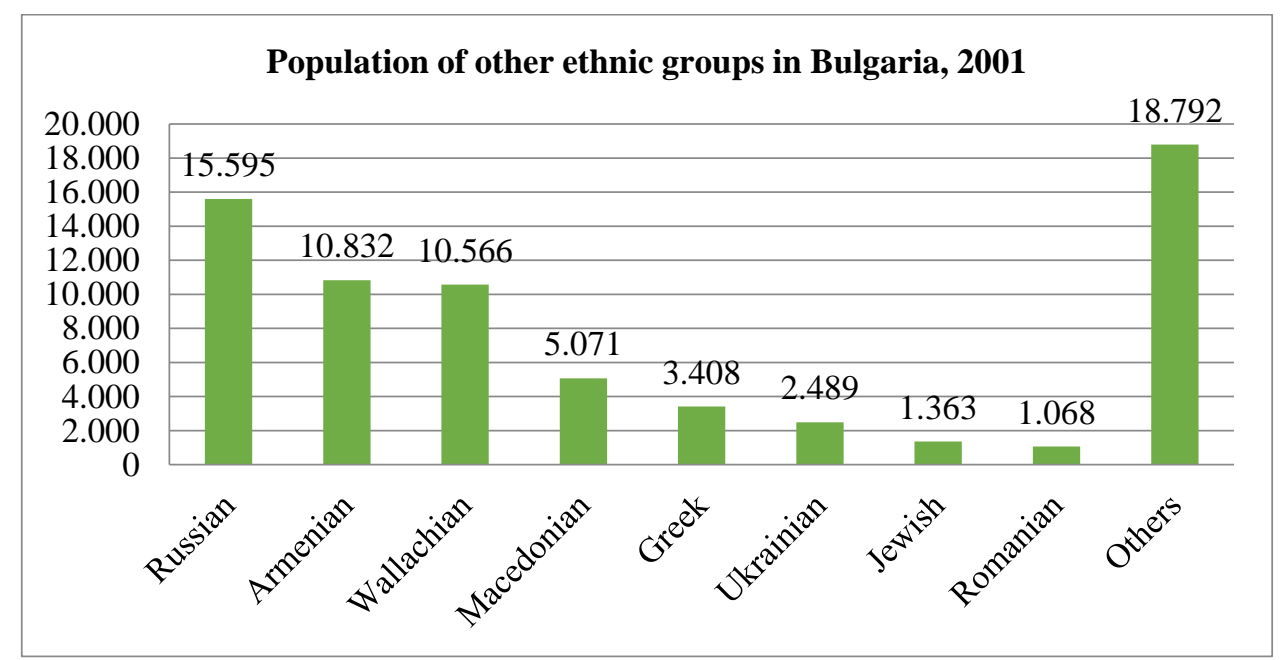

Figure 2. Population in other ethnic groups in Bulgaria, 2001

Source: NSI

\footnotetext{
${ }^{2}$ Ilieva, N. Number of the Roma ethnic group in Bulgaria from the Liberation (1878) to the beginning of the 21st century according to the censuses, BAS, Problems of Geography, Vol. 3-4, 2012
} 
Data from the last census show values of 325343 people or $4,9 \%$ of the country's population. However, these values cannot be considered to be fully exhaustive because of the so-called "preferential ethnic self-awareness" of the Roma, which is attributed to the ethnic group they live in. This is where the big differences between official and unofficial data come from, not only in Bulgaria, but in other countries with a Roma minority.

The Roma ethnic group is distinguished by higher fertility rates, which is considered an ethnic tradition; with higher mortality rates and lower life expectancy. But in addition to these indicators, there are also negative trends in educational attainment and in economic activity. For the sake of a successful integration policy, a set of measures are used and different integration models are used that can be said to produce positive results.

In addition to the three main ethnic groups, there are representatives of other ethnicities in Bulgaria, but with a lower number. These are the representatives of the Russian, Armenian, Wallachian, Macedonian, Greek, Ukrainian, Jewish and Romanian ethnic groups (fig. 2).

The data obtained in both censuses (2001 and 2011) have similar values, so we can point out that the Russian ethnic group is distinguished with a larger number of representatives, followed by the Armenian and the Vlachs. The lowest number of representatives is characterized by the Romanian group. Due to the voluntary nature of the issue of ethnicity, there is also a high percentage of people who did not specify an ethnic group or chose the "other" category.

\section{DEMOGRAPHIC SITUATION IN THE COUNTRY, PART OF THE ROMA POPULATION AND CHANGES IN THE NUMBER OF THE ROMA POPULATION IN THE XX AND XXI CENTURIES}

Although the demographic situation in Bulgaria has outlined a serious crisis of nearly 30 years, it is only in the last few years that it has become a topic of public debate and it has been argued that measures should be taken to improve it. However, this debate is headed in several wrong directions, the focus and the measures taken are not related to the most significant problems and this leads to lack of results. We are constantly talking about our low birth rates, the absolute decrease in the number of babies born each year and the aging of the population. Yes, they are a fact, but they are not the main problems, because in terms of the childbearing rate (the average number of children per woman of childbearing age) Bulgaria, with its 1,4, fits normally into the values of European countries, where this coefficient varies between 1,1 and 2. In the last few years, fewer and fewer babies have been born, in absolute numbers $(2017$ - 56,436), but this is normal, as the generation born in the 1990s now enters the infancy, but Bulgaria was already in a demographic crisis, i.e. the childbearing contingent of the population is continually shrinking, and of course, the continuing emigration of people of active age also contributes. Definitely Bulgaria is among with the oldest population not only in Europe but also in the world. And it is also the only country in all of human history where the largest cohort population is already at retirement age (60-64) - the female. But here we are witnessing a demographic paradox rather than a real problem with aging. Because we have one of the lowest average life expectancies in the EU (74.7 years) and the oldest population. This is due to the drastic vertical demographic imbalance in the ratio of young (up to 29 years) to adult (over 60) population. Here again we come to the main demographic problem of Bulgaria, which is related to the continuing permanent emigration of educated and qualified people in active age (18-50 years). So when we talk about demography in Bulgaria, we have to talk about 
one basic thing - the detention of young people in the country. To expect a sharply rise in fertility is not serious, even reaching a two-child family model through financial incentives is not realistic and will not solve our problems. But if we manage to keep our young people in the country as long as they give birth, it will put an end to the demographic collapse and gradually reduce imbalances. Moreover, in the 21st century in the digital, technological world, the battle of developed societies will no longer be for territory, the location of border pegs will be less important, it will not be for resources in the traditional sense - oil, coal. , ore, and it will be for human capital. Those societies that provide quality, young, educated and skilled human capital will thrive. And human capital can only be secured in two ways - either by creating it and retaining it in the country, or by attracting it from outside. In our current socio-economic reality, it is difficult to talk about attracting a large number of educated and skilled immigrants. Then we have only one thing left - detention in the country of the young people who we have today. The measures should be directed in two directions - education and quality realization (Burdarov, Ilieva, 2018). [3]

The demographic reality can be traced through national census data and current statistics. According to the values for 2018, the total population amounts to 7000039 people. At the moment we expect the results for 2019, from which it will be clear that the population of the country has reached values of less than 7 million. The population growth for the country is $-6,5 \%$, but the data in more districts are much more scary - there is no district with positive growth, the only exception are some areas with less high negative values, such as Sofia-capital and those with higher concentration of representatives of the Turkish and Roma ethnic group who they have traditionally higher reproductive attitudes. We observe a similar situation with the migration rate - external migration continues to maintain high levels, and at the local level we have traffic directed mainly from villages to large regional cities. This, in turn, hides socio-economic problems associated with the depopulation of the rural areas and the over-concentration of people in large cities.

There are other demographic indicators that are indicative of the crisis in the country. According to Naydenov and Traikov (2016), an important trend in population reproduction in both developed countries and our country is its aging. Since the middle of the XX century the aging process in Bulgaria has started to develop much more intensively. Among the causes that led to its acceleration are the decisive influence of the socio-economic changes in the country and the related directions of economic development and specialization. Migrations to larger cities and industrial centers and the spread of urban lifestyles predetermine the even greater decline in fertility rates and the proportion of children in the total population. The outflow of young people from the villages to the cities, which began in the 1950s and 1960s, relieves a considerable part of the employed in agriculture and at the same time accelerates the aging of the rural population. The negative changes in the age structure of the population in Bulgaria continue in the beginning of this century. In support of this is the data from the last two censuses. The part of the population aged 65 and over increased from 14,3\% in 1992 to $16,8 \%$ in 2001 and to $18,9 \%$ in 2011 . For the period 1992-2011, it increased by $4,6 \%$. There are changes in the age structure of the population. There is an increasing process of demographic aging, resulting in a reduction in the absolute number and relative part of the population below 18 years. In 2001, 19,4\% of the population were below the age of 18, while in 2011 their part decreased to $15,9 \%$. For the period 1992-2011, the decrease was $7,4 \%$. The part of the population in the age group 18-64 is increasing. Compared to 1992, this share increased by $1,7 \%$, from $62,2 \%$ to $63,9 \%$, and for the period 2001 to 2011 
we have increased by $1,3 \%$ from $63,9 \%$ to $65,2 \%$. [4]

The Roma ethnicity is characterized by a young age structure and the share of the loan maintains higher values. Considering the results of the last three censuses, it is concluded that this is the only ethnic group in the country to show an increase in its numbers, despite the significant discrepancy between official statistics and scientific and empirical demographics, which show even more higher increase of the Roma population in the country (Ilieva, 2013). [5]

The demographic processes by ethnic groups cannot be traced in sufficient detail due to the existing incompleteness and inaccuracies in the statistics. The reasons for this are that until 1946, the current statistical reporting was kept on religious grounds, since religion was the main distinguishing feature of the Turkish and Bulgarian ethnic groups. The issue is more complex with the Roma population, where from 1878 until the end of World War II it is very difficult to trace the particularities of demographic indicators, since 4/5 of them were registered as Muslims during this period and 1/5 are Christians. The incorrect, inaccurate accounting of the number of Roma, as well as the frequent changes in the territory of the country during this period also hinders the determination of the values of the basic coefficients characterizing natural reproduction then. The cultural characteristics of the Roma and Turkish populations and their socio-economic characteristics, it can be assumed that their demographic development is similar. The Roma population growth in the years from the beginning of the twentieth century to the Second World War is in the order of 18-20\%, and given that mortality is also formed by high values (about $20 \%$ ), it can be concluded that the birth rate was over $40 \%$. $^{3}$

In the period after 1946, a new political regime emerged in Bulgaria, in which the Roma were already with minority status. The data on their numbers from that period have not been presented, and according to declassified documents, along with some of the official censuses, secrets from the Ministry of Interior were kept. During the socialist period, it appeared that there was a decrease in the number of Roma.

According to Ilieva (2013), the practice of undisclosed "secret" censuses of the population (and especially of Gypsies) through the Ministry of Interior continues. The last such census is from January 1989 for the needs of the revival process, which accounts for 576 927 Gypsies (or $6.45 \%$ of the Bulgarian population), with a note indicating that more than half of them are with preferential Turkish ethnic identity. A similar census of Gypsies along the line of the Ministry of the Interior was conducted in May 1992, which is however incomplete and according to which in Bulgaria the Roma number are 550000. Since then, until the last census, the number of Roma has been constantly fluctuating, with just over $370000(4,7 \%)$ in 2001 and about 325000 (4,9\%) in 2011. As with the latter, the percentage is higher due to the overall decrease in population. According to unofficial data, it is estimated that the Roma ethnic group is represented by about 750 000, but these are data that cannot be documented due to the voluntary nature of the category and the specificity of their ethnic identity already mentioned here.

Exactly these high values that necessitate the implementation of integration policies that help to increase educational attainment, economic activity, employment, and their general social status.

\footnotetext{
${ }^{3}$ Ilieva, N. The Roma in Bulgaria. Number and localization of the Liberation (1878) until the beginning of the 21 st century, BAS, S., 2013
} 


\section{ISSUES RELATED TO THE ROMA ETHNIC GROUP AND SUCCESSFUL INTEGRATION MODELS}

According to Burdarov and Ilieva (2019) it is very important to note that regardless of which country the Roma live in, regardless of its economic development and form of government, the problems with them are the same. They can be equally identified in Finland, Spain, Bulgaria, and Turkey. However, this in turn enables successful integration models in one country to be applied in others through some adaptation.

A very important question that is the key to their successful integration is to understand their complex social stratification, which is not ethnic or linguistic, but is related to origin, clan, craft, social status. Because there are Roma groups that are not only inclined to integrate, but also strongly want them, and need to be supported by the state and society, but there are also some who the thought of integration cannot reach at all. This requires a differentiated approach and a lot of work directly on the ground with people who are familiar with the ethno-psychology and behavior of the individual Roma groups.

In recent years there has been talk of quite successful integration models and policies implemented in different parts of Spain, Finland, Slovakia, Czech Republic, Hungary, which shows that, although difficult integration of Roma is possible. The question is to understand why and how some models work and how they can be applied in other places where a compact Roma population lives.

There are borrowed models in Bulgaria that are successful and produce positive results. Burdarov and Ilieva (2013), however, formulate several characteristics of the Roma ethnic group, which are major obstacles to successful integration:

- the ethno-psychology of the Roma, characteristic of the Indian subcontinent, but difficult to fit into the European value system;

- the perception of the Roma as a homogeneous group and the misunderstanding of their complex social stratification;

- ghettoization, which reproduces the negative behaviors of Roma and increases their social rejection and segregation;

- the low level of education and non-speaking of the Bulgarian language, which also deepens their isolation and difficult integration into the social life forms;

- existing prejudices and fears, both from the other ethnic groups towards the Roma and from all others;

- the emphasis in the media and the public arena only on the negative aspects of Roma life and the negative examples related to them ;

- the overt reluctance of individual Roma groups to make any effort to integrate into society and play the role of "learned helplessness" and the obligation of the state to care for them; Hungary is a country with a significant Roma minority, which according to official data is 315583 people (according to the 2011 census), but the actual number is between 700,000 and 900,000 or almost $10 \%$ of the country's population. In Hungary, three major Gypsy groups are distinguished: the first Hungarian Romangri, the Roma whose first language is Romani and the Bisha, who speak the archaic Banat dialect of Romanian.

One of the most successful examples of Roma integration is from the town of Pécs in southwestern Hungary. The successful model here is educational and involves two schools. The method used is training in Bishops and other Gypsy languages, as well as acquaintance with the specificity of Roma culture, as this does not happen in any isolated Roma classes, but in all classes and groups in the school, i.e. here we have a typical 
example for multicultural and multilingual education. In the afternoon, there are free Bishops only classes run by a bish social worker. The idea is that using their mother tongue, children are more motivated to learn and also easier to understand the material, but they are also required to know the Hungarian language very well. In addition, extracurricular classes in theatrical arts, folklore (Bishops and Hungarians), gardening and cooking are organized in which both Hungarian and Bishops are used simultaneously. The school library is one of the best secured books in the country, and at the same time records a record number of book visits and bookings in recent years. Every thursday, the doctor also conducts interviews with students regarding their health, sexual and hygiene culture.

Despite the sense of failure of integration policies in Bulgaria, we also have some positive examples from recent years. The village of Dolni Tsiber in northwestern Bulgaria became known as the "Roma Cambridge", as almost all young people there of Roma origin have completed secondary education and over $10 \%$ have a college degree. There are other such positive examples from Kavarna, from Kuklen, with the exception of these places the success is due to the implementation of the multicultural approach in education and serious, responsible attitude on the part of the local government.

The last and most interesting example is from the town of Straldzha, Yambol region, where the ratio of Bulgarians to Roma is almost 50 to $50 \%$, with a population of $6372 \mathrm{e}$. (2015). And of course there are serious problems, as in other places with compact Roma population in Bulgaria. However, the local government decided to take serious measures to tackle these problems. One of the most serious is thefts of agricultural produce during the summer and autumn seasons that has been mastered by the creation of a municipal guard, which includes Roma. But undoubtedly, what distinguishes the city in terms of its integration policy and is a shining example is the success of Roma inclusion in the education system. During the 2017-2018 school years At the St. Cyril and Methodius School, which provides $100 \%$ Roma students with education, at the proposal of the MLSP, the "Icelandic Model" was implemented to deal with aggression and dropout. What is the "Icelandic Model" and how can it be implemented in Roma neighborhoods, provided that there is no Roma minority in Iceland? In the early 90's of XX century. in Iceland it is found that there is a major problem with alcohol and drug use among students, as well as with school aggression, something that is characteristic of developed European societies, except that they are deeper in Iceland because of the purely climatic and psychological causes - the long polar night, the cold, windy and gloomy climate. A large percentage of young people find a solution in alcohol, drugs, aggression among them is at very high levels. The government is inviting American psychologist Harvey Milkman, who along with local psychologist Goodberg Johnson and researcher Dora Sigfussdotir, tackle the daunting task of finding a decision for these serious problems. The main question you have asked yourself is whether it is possible to offer young people a healthy and useful alternative to alcohol, drugs and unreasonable aggression. And the idea is all to be preventative, not to look for solutions when the problems are irreversible. [6]

\section{CONCLUSION}

In conclusion we can say that Roma integration is one of the main challenges for the future of Bulgaria. It is expected that by 2050 they will be about 1100 000-1 200000 people, or $21-22 \%$ of the population of the country and urgently need to take measures for their successful integration. Despite prejudices and typically Bulgarian skepticism, this population is here and will continue to live here, so it is the responsibility of the whole 
society to work for their integration. This is already a question for the future of the country. Practice in our country, as well as in other countries, shows that Roma integration is a very complex case, but not insoluble. Our experience in the town of Straldzha proves that it must be started by those Roma communities that are inclined to integrate and simply need to be supported, financially and logistically, by local and state authorities for this. In all situations, when it comes to Roma integration, we need to talk about education first. Only education can change the way people think and behave, and only through education they can be actively included in the labor market, which is very important for Bulgaria and because of the acute shortage of labor, which will deepen in the coming decades. Despite the difficulties and mistrust in society, we remain optimistic about the integration of Gypsies in the country and believe that this may happen in the foreseeable future.

\section{REFERENCES:}

[1] Huntington, S. The Clash of Civilizations and the remaking of world order, publ. house "Obsidian", 1996

[2] Ilieva, N. Number of the Roma Ethnic Group in Bulgaria from the Liberation (1878) to the Beginning of the 21 st Century According to the Censuses, BAS, Problems of Geography, vol. 34, 2012

[3] Burdarov, G., N. Ilieva Horizon 2030. Demographic tendencies in Bulgaria, Friedrich Ebert Foundation, 2018

[4] Naydenov, K1., T. Traykov Population Aging in Bulgaria - Trends, Features and Regional Differences, Sat. reports from the scientific conference "Geographic aspects of planning and use of the territory in the conditions of global changes", Varshets, 2016

[5] Ilieva, N. The Roma in Bulgaria. Number and localization of the Liberation (1878) until the beginning of the 21 st century, BAS, S., 2013

[6] Burdarov, G., N. Ilieva Demographic specifics of (in) possible Roma integration, Friedrich Ebert Foundation, 2019.

[7] www.nsi.bg 